\title{
Performance Test and Temperature Simulation of Pilot Scale Thermal Plasma System for Fluff SRF Treatment
}

\author{
Received January 22, 2020; accepted January 31, 2020
}

Kyu-Hang Lee ${ }^{a}$, Tae-Wook Kimª, Pil-Jung Kimª, Soo-Min Lee ${ }^{a}$, Jae-Yun Lee ${ }^{b}$, Jea-Hyung Lee ${ }^{b}$, Sun-Dong Lee ${ }^{b, *}$, and Byung-Koo Son ${ }^{\mathrm{a}, *}$

a Division of Plasma Convergence R\&BD, Cheorwon Plasma Research Institute, Gangwon-do 24047, Republic of Korea

${ }^{\text {b} T e c h n o l o g y ~ T e a m, ~ S u n g S h i n ~ C e m e n t, ~ C h u n g c h e o n g b u k-d o ~ 27008, ~ R e p u b l i c ~ o f ~ K o r e a ~}$

\section{*Corresponding author E-mail: A95034@sscem.com, byungkoo@cpri.re.kr}

\section{ABSTRACT}

The improvements in daily living introduced by industrial development are at the expense of the environment. With an increasing interest in flammable waste, it is becoming important to reduce the volume of air pollutants in the waste disposal process and use energy efficiently. There is a need for a system that can increase thermal efficiency while incinerating solid refuse fuel (SRF) products manufactured using combustible waste. Thermal plasma gasification and combustion composite systems are technologies that take advantage of combustion and gasification. An SRF input at 2 ton/h was treated using thermal plasma, and the operating temperature in the reactor was maintained at $1024{ }^{\circ} \mathrm{C}$ or higher. The exhaust gas at this time was measured at $7.08 \% \mathrm{H}_{2}, 0.22 \% \mathrm{CH}_{4}$, and $9.26 \% \mathrm{CO}$.

Keywords: Fluff solid refuse fuel, Gasification, Waste plastic, Plasma system

\section{Introduction}

Environmental pollution is accelerating because of an increase in various wastes generated by industrial development towards the improvement of living standards. Accordingly, the amount of plastics generated as waste is also increasing, and this has led to research attention being focused on developing a method of treat waste plastics. Existing landfill facilities have reached their limit, and therefore, there is a growing social concern regarding the shortage of landfill facilities and environmental pollution treatment. Thus, there is a need to develop environment-friendly technologies that can convert waste plastics into energy resources. In this study, we designed and fabricated a complex system via a pilot scale thermal plasma for solid fuel recycling of plastics of gasification and combustion to process large-capacity solid refuse fuel (SRF), and to study reactor temperature characteristics and generated gases [1-5].

Direct incineration is a method of directly oxidizing organic materials by supplying a large amount of air; waste heat and various oxidizing pollutants are generated as by-products. In the pyrolysis gasification melting method, organic materials are synthesized in a reducing atmosphere and inorganic materials are melted to produce slack and recycled. Table I summarizes the differences between the two systems.

The characteristics of the pyrolysis gasification melting technology are as follows: 1) $\mathrm{C}$ and $\mathrm{H}$ components in the waste are converted to $\mathrm{CO}$ and $\mathrm{H}_{2}$, thereby minimizing energy loss due to cooling; 2) The material decomposition process is performed in a reducing atmosphere under a low oxygen state, and the total amount of gas to be treated is small and no harmful substances are generated. The generated substances are decomposed during the high temperature gasification reaction, which is economically and environmentally advantageous over incineration; and 3) Easy disposal of waste tires, waste plastics,

Table I. Comparison between incineration and gasification.

\begin{tabular}{ccc}
\hline Operating & Incineration & Gasification \\
\hline $\begin{array}{c}\text { temperature } \\
\text { Operating pressure }\end{array}$ & $\sim 1000{ }^{\circ} \mathrm{C}$ & $>1300{ }^{\circ} \mathrm{C}$ \\
\hline $\begin{array}{c}\text { Reproduction status } \\
\text { Atmospheric }\end{array}$ & Ash & High pressure \\
Principal reaction & $\mathrm{C}+\mathrm{O}_{2}=\mathrm{CO}_{2}$ & $\mathrm{Slag}$ \\
& $\mathrm{H}_{2}+\frac{1}{2} \mathrm{O}_{2}=\mathrm{H}_{2} \mathrm{O}$ & $\mathrm{C}+\mathrm{H}_{2} \mathrm{O}=\mathrm{CO}+\mathrm{H}_{2}$ \\
& $\mathrm{C}+\mathrm{CO}_{2}=2 \mathrm{CO}$
\end{tabular}


waste oil sludge, and sludge.

\section{Experimental details}

\subsection{Fluff solid refuse fuel (SRF)}

Fluff SRF used in this study is a waste plastic solid fuel compressed to a dimension of $50 \mathrm{~mm}$ by crushing it into a wrapping paper, bag, plastic, etc. Table II shows the result of the proximate analysis and the ultimate analysis. The results showed that the carbon content had a large proportion (61\%), and $\mathrm{H}, \mathrm{O}, \mathrm{N}, \mathrm{S}$, and $\mathrm{Cl}$ had concentrations of $8.59,17.26,0.78,0.41$, and $0.79 \%$, respectively. The LHV was $5,990 \mathrm{kcal} / \mathrm{kg}$.

\subsection{Equipment}

The system consists of an SRF metering equipment, and a reactor equipped with a thermal plasma torch.

\section{Thermal plasma torch}

Figure 1 shows the $3 \mathrm{D}$ and actual view of the thermal plasma torch. The plasma torch is heated by the arc gas injected by the arc discharge generated between the cone-shaped cathode tungsten rod and the nozzle-shaped anode, which is designed to be ejected in the form of a high-temperature, high-velocity plasma jet.

\section{SRF feeder}

The feeder is a device that can quantitatively input SRF at a rate of 1-5 ton/h without agglomeration; a double screw and a paddle is installed to remove agglomerates.

\section{Gasification and combustion system}

The gasification and combustion system is equipped with thermal plasma torches to increase the temperature in the reactor. The SRF is supplied to the combustion reactor via the SRF connection passage in the upper portion, and it has a structure that is discharged by burning and gasifying through the plasma torch region. Inside the reactor, a refractory was installed to prevent damage during high temperatures, and a K-type thermocouple was installed to measure the temperature inside the reactor. For gas analysis, an analysis line was

Table II. Characteristics of SRF.

\begin{tabular}{|c|c|c|}
\hline $\begin{array}{l}\text { Refuse plastic fuel analysis } \\
\text { method }\end{array}$ & Contents & Valve \\
\hline \multirow{4}{*}{$\begin{array}{l}\text { Proximate analysis } \\
\text { (\%) }\end{array}$} & Moisture & 7.6 \\
\hline & Volatile & 71.7 \\
\hline & Ash & 10.8 \\
\hline & Fixed carbon & 9.9 \\
\hline \multirow{6}{*}{$\begin{array}{l}\text { Ultimate analysis } \\
\qquad(\%)\end{array}$} & $\mathrm{C}$ & 60.69 \\
\hline & $\mathrm{H}$ & 8.59 \\
\hline & $\mathrm{O}$ & 17.26 \\
\hline & $\mathrm{N}$ & 0.78 \\
\hline & S & 0.41 \\
\hline & $\mathrm{Cl}$ & 0.79 \\
\hline
\end{tabular}

installed at the bottom of the reactor using a sus tube, and the gas analysis was performed using GC (3000 micro GC, Inficon, Switzerland)

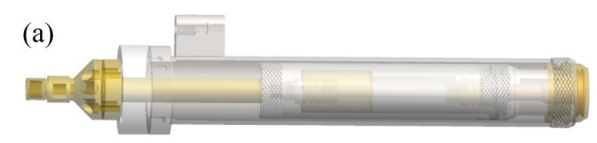

(b)

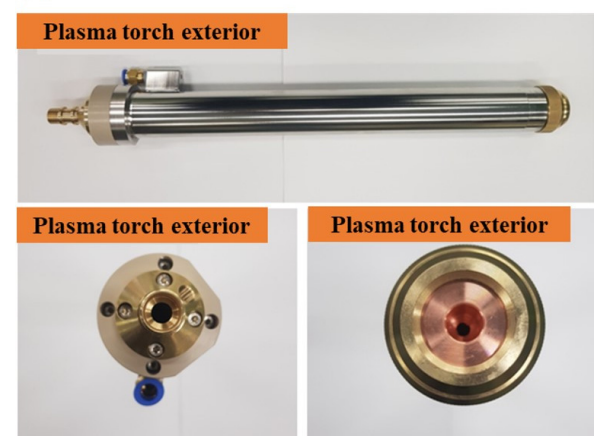

Figure 1. (Color online) (a) 3D exterior drawing of plasma torch. (b) Fabricated plasma torch.

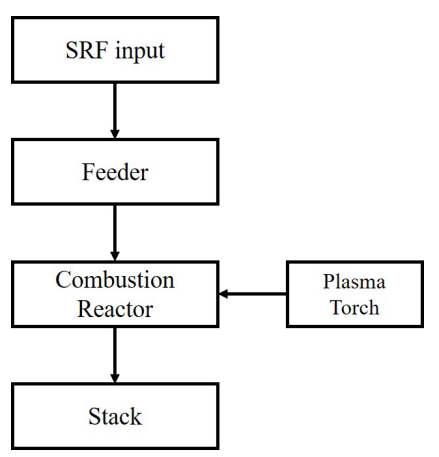

Figure 2. Flow chart of thermal plasma gasification and combustion complex systems.

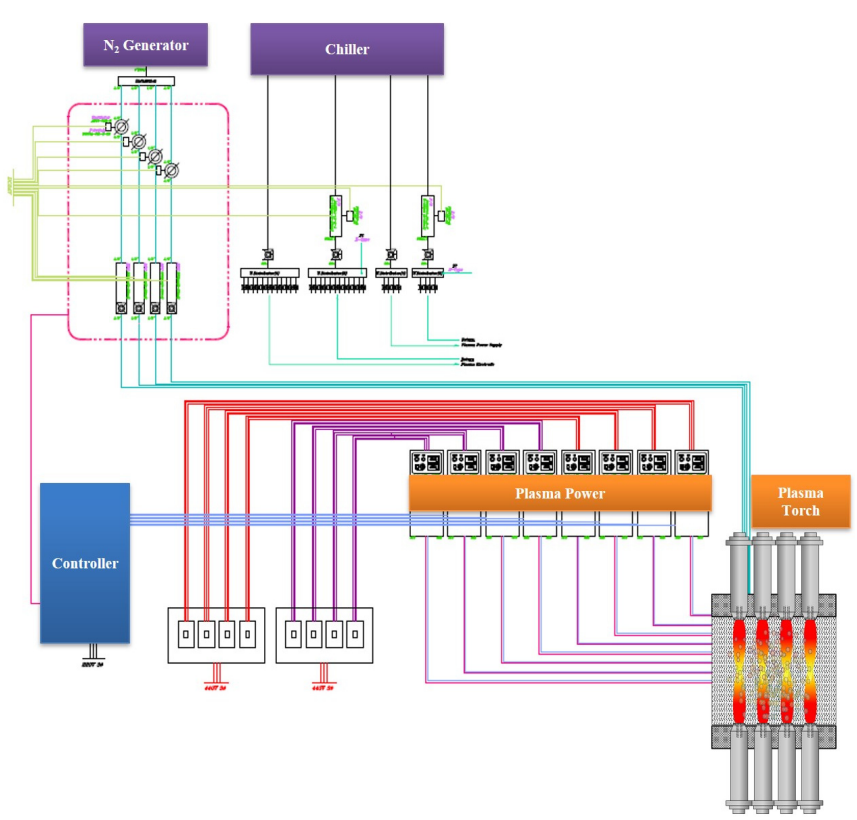

Figure 3. (Color online) Configuration of plasma system. 
Table III. Thermal plasma torch working condition.

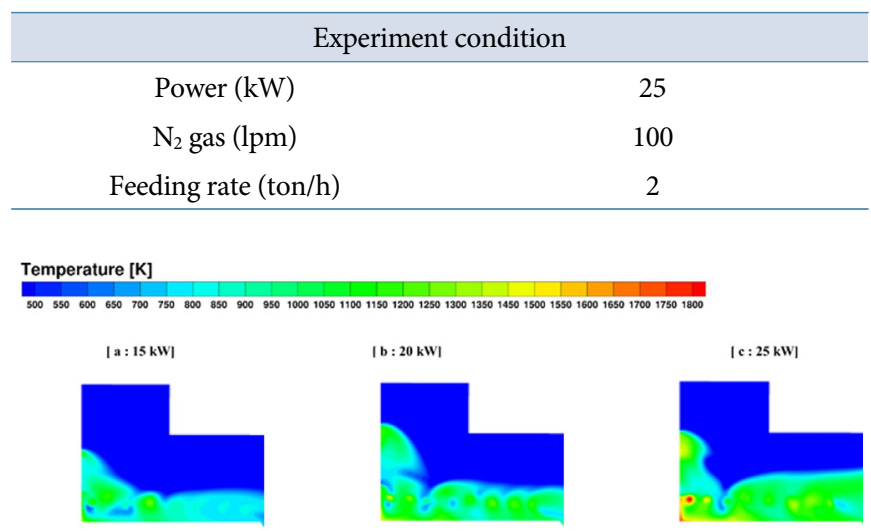

Figure 4. (Color online) Z-plane temperature distribution in the system according to the output change of thermal plasma generator.

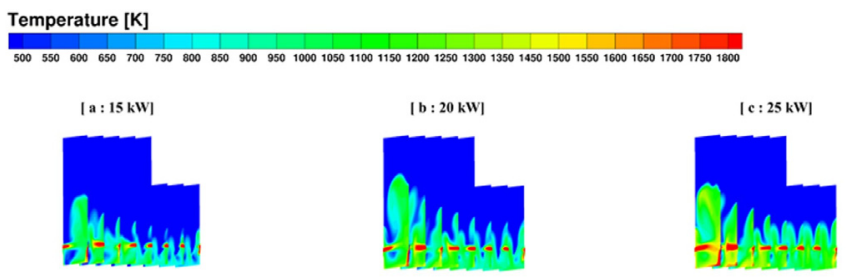

Figure 5. (Color online) X-plane temperature distribution in the system according to the output change of thermal plasma generator.

and gas analyzer (Vario plus, MRU, US). Figure 2 shows the flow chart of thermal plasma systems, while Fig. 3 shows the configuration of the plasma system.

\section{Experiment method}

SRF is fed into the gasification and combustion system at a feed rate of 2.0 ton/h through the fixed supply system. The process conditions of the thermal plasma torch installed in the reactor are summarized in Table III.

Samples were prepared at the top of the reactor before the temperature in the reactor was raised, and the SRF was added $10 \mathrm{~min}$ after plasma discharge. $\mathrm{CO}, \mathrm{CO}_{2}, \mathrm{O}_{2}, \mathrm{H}_{2}$, and $\mathrm{CH}_{4}$ were measured using gas analysis equipment, and $\mathrm{NOx}, \mathrm{HCl}, \mathrm{CO}$, and $\mathrm{CO}_{2}$ were analyzed by TMS at the final exhaust port.

\section{Results and discussion}

\subsection{Simulation}

Computational analysis was performed to check the thermal temperature inside the waste plastic treatment system according to the plasma torch output. The computational analysis used ANSYS-FLUENT, a CFD analysis code. The boundary conditions for computational analysis were set up with air and plastic inlets, walls, outlets, and thermal plasma inlets.

Figure 4 compares the temperature distribution in the Z-plane over the entire area at the center of the treatment system, and Fig. 5 shows the X-plane temperature distribution at each point in the treatment system. The results show that as the power increases, the

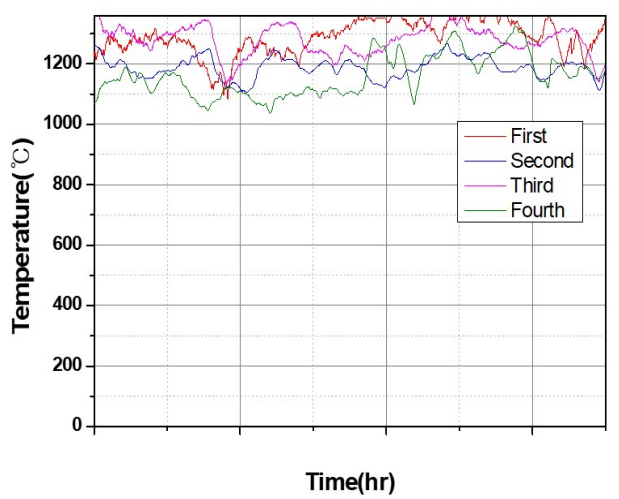

Figure 6. (Color online) Temperature inside the combustion system.

Table IV. Pyrolysis gas generated after pyrolysis.

\begin{tabular}{ccccccc} 
& 1 & 2 & 3 & 4 & 5 & Average \\
\hline $\mathrm{CO}(\%)$ & 8.2 & 9.3 & 10.3 & 9.3 & 9.2 & 9.26 \\
$\mathrm{CO}_{2}(\%)$ & 10 & 9.9 & 9.3 & 9.9 & 9.9 & 9.80 \\
$\mathrm{O}_{2}(\%)$ & 0.2 & 0 & 0 & 0 & 0 & 0.04 \\
$\mathrm{H}_{2}(\%)$ & 6.2 & 7.1 & 7.8 & 7.1 & 7.2 & 7.08 \\
$\mathrm{CH}_{4}(\%)$ & 0.2 & 0.3 & 0.2 & 0.2 & 0.2 & 0.22 \\
\hline
\end{tabular}

temperature inside the system increases and becomes uniform. When using a high output thermal plasma generator, it is expected that the high temperature region of the thermal plasma will be attracted by the rapid flow in the axial direction, and the temperature inside the system is expected to increase.

\subsection{Reactor temperature change}

Figure 6 shows the results of measuring the temperature of the combustion reactor four times for $7 \mathrm{~h}$. The temperature sensor is a K-type sensor and it can measure up to $1360{ }^{\circ} \mathrm{C}$. The measurement resulted in a temperature distribution of $1024-1360{ }^{\circ} \mathrm{C}$. The temperature inside the reactor, however, is over $1360{ }^{\circ} \mathrm{C}$.

\subsection{Pyrolysis gas analysis results}

The main reaction to obtain the syngas, which is the main component of $\mathrm{CO}$ and $\mathrm{H}_{2}$ from SRF, is largely composed of the partial combustion reaction of the $\mathrm{CO}$ and $\mathrm{H}_{2}$ components in the waste with the externally supplied oxygen and the gasification reaction of this combustion product with the unreacted carbon in the SRF.

The partial combustion reaction is a combustion reaction in which the $\mathrm{C}$ and $\mathrm{H}_{2}$ components, and the oxygen in the SRF react; the amount of oxygen supplied from the outside is less than the amount of oxygen required for complete waste combustion. The gasification reaction is a gaseous reaction of unreacted carbon and a combustion product formed by a partial combustion reaction in a high temperature atmosphere; further, a synthesis gas containing $\mathrm{CO}$ and $\mathrm{H}_{2}$ as a main component is generated. Table IV lists the exhaust gas analysis table measured at the bottom of the reactor.

The exhaust gas analysis at the outlet of the combustion system showed $\mathrm{CO}=9.26 \%, \mathrm{H}_{2}=7.08 \%, \mathrm{O}_{2}=0.04 \%$, and $\mathrm{CH}_{4}=0.22 \%$. The developed combustion system can confirm that combustion and gasification occur simultaneously. 
Table V. Exhaust gas analysis.

\begin{tabular}{ccccc}
\hline & $\begin{array}{c}\mathrm{NOx} \\
(\mathrm{ppm})\end{array}$ & $\begin{array}{c}\mathrm{HCl} \\
(\mathrm{ppm})\end{array}$ & $\begin{array}{c}\mathrm{CO} \\
(\mathrm{ppm})\end{array}$ & $\begin{array}{c}\mathrm{CO}_{2} \\
(\%)\end{array}$ \\
\hline TMS & 189.36 & 0.05 & 498.77 & 15.21 \\
\hline
\end{tabular}

\subsection{Exhaust gas measurement result}

The analysis was performed using TMS installed in the chimney. Table $\mathrm{V}$ shows the result of $\mathrm{NOx}, \mathrm{HCl}, \mathrm{CO}$, and $\mathrm{CO}_{2}$ measurements.

\section{Conclusions}

In this study, temperature and gas composition in the reactor were studied through the gasification and combustion system using fluff SRF. Computational analysis was also performed on the internal environment of the combustion system according to the change in the output of the thermal plasma generator. As the generator output increases, the temperature inside the system increases, and the temperature becomes uniform for the entire area. These results indicate that as the generator's output power increases, the high-temperature region of the thermal plasma extends to the center of the system as the axial velocity increases. Thus, the high output thermal plasma generator can be expected to attract thermal plasma by the rapid flow in the axial direction and lead to a temperature increase inside the system.

SRF was found to show a high temperature of at least $1024-1360$
${ }^{\circ} \mathrm{C}$ above the continuous treatment of 2 ton/h, while $\mathrm{CO}$ and $\mathrm{H}_{2}$ concentrations increased based on the gas analysis. The reactor analysis confirmed that combustion and gasification occur simultaneously. In addition, the pollutant gas discharged to the atmospheric gas phase could be treated under environmental regulations. The results confirm that the gasification and combustion composite system can handle various samples.

\section{Acknowledgements}

This work was supported by Korea Environment Industry \& Technology Institute (KEITI) though Advanced Technology Program for Environmental Industry, funded by Korea Ministry of Environment (MOE) (RE201809036).

\section{References}

[1] Y. N. Chun, M. S. Lim, and D. Y. Dae, J. Kor. Soc. Environ. Eng. 37, $636(2015)$

[2] F. Lebrun, H. Marzouk, and P. Pasquini, J. Chem. Technol. Biotechnol. 77, 315 (2002)

[3] I. H. Hwang, J. Kobayashi, and K. Kawamoto, Waste Manage. 34, $402(2014)$

[4] M. F. Zhukov, Plasma Dev. Oper. 5, 1 (1996)

[5] S. C. Kim, M. S. Lim, and Y. N. Chun, Int. J. Hydrogen Energy 37, 14458 (2013) 